\title{
Características de fermentação e composição químico-bromatológica de silagens de capim-tifton 85 confeccionadas com cinco teores de matéria seca ${ }^{1}$
}

\author{
Flávio Geraldo Ferreira Castro², Luiz Gustavo Nussio ${ }^{3}$, Cláudio Maluf Haddad³ ${ }^{3}$,ábio Prudêncio \\ de Campos $^{4}$, Rodrigo Michelini Coelho ${ }^{5}$, Lucas José Mari ${ }^{6}$, Paulo de Almeida Toledo ${ }^{7}$ \\ ${ }^{1}$ Parte da tese de Doutoramento do primeiro autor apresentada à USP/ESALQ - Piracicaba, SP. Financiamento: CAPES e Fazenda Água \\ Comprida-MG. \\ 2 Doutor em Agronomia - Agrocria Com. e Ind. Ltda - Goiânia - GO. \\ ${ }^{3}$ Departamento de Zootecnia - USP/ESALQ. Av Pádua Dias, 11, CEP: 13418-900-Piracicaba, SP. \\ ${ }^{4}$ Instituto de Zootecnia - IZ, Rua Heitor Penteado, 56 CP.60, CEP: 13460-000 - Nova Odessa, SP. \\ ${ }^{5}$ Agroceres Nutrição Animal - Belo Horizonte- MG. \\ ${ }^{6}$ Pós-Graduação em Ciência Animal e Pastagens, USP/ESALQ \\ ${ }^{7}$ Fazenda Água Comprida, C.P. 174 - CEP: 38010-010 - Uberaba, MG.
}

RESUMO - Objetivou-se avaliar o efeito do emurchecimento e da aplicação de aditivo bacteriano-enzimático (ABE) ou ácido propiônico tamponado (APT) sobre as características de fermentação e a composição química da silagem de capim-tifton 85 (Cynodon spp.) armazenada em forma de fardos retangulares revestidos de filme plástico. Foram confeccionadas cinco silagens $(250,350,450,550$ e $650 \mathrm{~g} / \mathrm{kg} \mathrm{MS})$ sem aplicação de ABE (SA), três $(250,450$ e $650 \mathrm{~g} / \mathrm{kg}$ MS) com aplicação de $\mathrm{ABE}(\mathrm{CA})$ e uma $(650 \mathrm{~g} / \mathrm{kg} \mathrm{MS})$ foi pulverizada com uma solução contendo APT. As amostras foram colhidas nos tempos zero hora antes da ensilagem e 6,12 horas, 1, 2, 4, 8, 16,32, 90 e 180 dias após a ensilagem, para se estabelecer a tendência das características de fermentação e composição química. O delineamento experimental utilizado foi inteiramente casualizado, com três repetições, em parcelas subdivididas no tempo, sendo os tratamentos os fatores das parcelas, arranjados em esquema fatorial 5 × 2 incompleto. O emurchecimento a teores médios de MS (450 g/kg MS) favoreceu os parâmetros de fermentação ( $\mathrm{pH}, \mathrm{N}-\mathrm{NH}_{3}$ e poder tampão) e a composição química das silagens de capim-tifton 85. O uso de APT não melhorou as características qualitativas de fermentação e a composição química das silagens. A utilização de ABE apresentou mínimos benefícios somente nas silagens contendo elevado teor de matéria seca (650 g/kg MS), sendo ineficiente para forragens contendo alto teor de umidade $(250 \mathrm{~g} / \mathrm{kg} \mathrm{MS})$.

Palavras-chave: ácido propiônico, aditivo bacteriano, emurchecimento

\section{Fermentation characteristics and chemical composition of tifton 85 silages with different dry matter contents}

\begin{abstract}
The objectives of this study were to evaluate the effects of wilting and the application of bacterial enzymatic additive (BEA) or buffered propionic acid (BPA) on the fermentation characteristics and chemical composition of Tifton 85 (Cynodon spp.) silage stored in big square bales wrapped with plastic sheet. The experimental treatments were: five forage dry matter contents $(250,350,450,550$ and $650 \mathrm{~g} / \mathrm{kg} \mathrm{DM})$ without BEA (WoA), three forage dry matter contents $(250,350$ and $650 \mathrm{~g} / \mathrm{kg} \mathrm{DM})$ with BEA (WA) and an wilted forage $(650 \mathrm{~g} / \mathrm{kg} \mathrm{DM})$ sprayed with BPA. Corn silage samples were taken after 0, 6 and 12 hours and 1, 2, 4, 8, 16, 32, 90 and 180 days of storage to assay for the fermentation and chemical characteristics time trends. The experimental design was completely randomized with three replications with a split plot feature of experimental treatments as main plots and fermentation times as split plot treatments. Wilting to $450 \mathrm{~g} / \mathrm{kg}$ DM did improve fermentation parameters $\left(\mathrm{pH}, \mathrm{N}-\mathrm{NH}_{3}\right.$ and buffering capacity) and chemical composition of Tifton grass silages. BPA addition did not improve the silage fermentation parameters neither chemical composition. The addition of BEA showed marginal benefits only in the high dry matter content silages $(650 \mathrm{~g} / \mathrm{kg} \mathrm{DM})$, with no significant changes in low dry matter silages $(250 \mathrm{~g} / \mathrm{kg} \mathrm{DM})$.
\end{abstract}

Key Words: wilting, microbiological additive, propionic acid

\section{Introdução}

As forragens tropicais caracterizam-se pela elevada produção de massa seca, com estacionalidade marcante entre as estações das "águas" e das "secas". A distribuição desuniforme de produção indica grande potencial para conservação de forragens, tanto por meio da ensilagem como pela fenação. Entretanto, somente nos últimos anos, a silagem de gramíneas tropicais conquistou seu espaço nos sistemas de produção de bovinos no país, embora estudos específicos envolvendo a ensilagem dessas gramíneas tenham sido realizados desde o final da década 
de 60 (Balsalobre et al., 2001). O provável motivo da reduzida utilização de silagens de gramíneas tropicais parece ter sido a falta de equipamentos apropriados para o corte e a colheita de plantas de alto potencial de produção. Nos últimos 15 anos, algumas empresas nacionais passaram a desenvolver e produzir equipamentos de maior capacidade operacional, viabilizando o uso de silagens em maior escala. Nos países da Europa, mais de $90 \%$ da forragem produzida é armazenada na forma de silagem.

Quantidades adequadas de substrato fermentescível, poder tampão relativamente reduzido e conteúdo de matéria seca acima de $300 \mathrm{~g} / \mathrm{kg}$ MS são características importantes para obtenção de padrões desejáveis de fermentação e conservação de forragens por meio da ensilagem (McDonald et al., 1991). Considerando a importância desses fatores inerentes a forragens tropicais, na ensilagem deve-se considerar que essas gramíneas apresentam baixas concentrações de carboidratos solúveis $(\mathrm{CHO})$, inferiores às das gramíneas temperadas, e pequenos teores de matéria seca nos estádios de crescimento em que apresentam bom valor nutritivo (McDonald et al., 1991). Essas características prejudicam o processo de conservação e podem promover fermentações secundárias, refletindo negativamente em perdas de matéria seca (McDonald et al., 1991). Limitações dessa natureza podem ser parcialmente controladas pelo aumento na porcentagem de matéria seca, pelo emurchecimento ou pela utilização de aditivos que contribuam para acelerar e estabilizar a fermentação: os aditivos bacterianos e as enzimas. Nos Estados Unidos e na Europa, essas técnicas têm sido bastante utilizadas com a finalidade de atenuar esses problemas, tanto de umidade quanto de baixa concentração de açúcares.

A técnica do emurchecimento possibilita a ensilagem de plantas forrageiras colhidas com baixo teor de matéria seca, em um processo simples, em que as fermentações indesejáveis são facilmente controladas pela diminuição da atividade de água (Aa) ou elevação da pressão osmótica (McDonald et al., 1991). Monteiro (1999) sugere que a elevação no teor de matéria seca para 350 a $400 \mathrm{~g} / \mathrm{kg}$ seria fator determinante da boa qualidade da silagem emurchecida.

Outra alternativa para melhoria do padrão fermentativo de silagens seria o uso dos aditivos bacterianos, adicionados durante a ensilagem de forragens para estimular a fermentação lática, resultando em rápida e intensiva produção de ácido lático, acelerando a queda de $\mathrm{pH}$, melhorando a preservação e minimizando perdas (Pitt, 1990). O uso de aditivos bacterianos ou enzimáticos tem-se mostrado eficiente em acelerar o processo de fermentação, reduzir a perda de nutrientes e a degradação de proteína e melhorar a digestibilidade da fibra e o valor nutritivo das silagens (McDonald et al., 1991). Contudo, há muitos resultados contraditórios para diversas forragens tropicais.

Atualmente, na Europa e nos Estados Unidos, os aditivos bacterianos são os mais comumente utilizados na ensilagem de milho, gramíneas e leguminosas, que podem ser emurchecidas até níveis superiores a $300 \mathrm{~g} / \mathrm{kg}$ MS. Essa associação entre emurchecimento e uso de aditivos visa melhorar a fermentação e o valor nutritivo da silagem (Mühlbach, 2000). Entretanto, não há aditivos eficientes para o controle da instabilidade aeróbia das silagens, mas a adição dos ácidos propiônico e benzóico pode, em alguma extensão, melhorar a estabilidade (Lindgren, 1999). O ácido propiônico tem sido efetivo em prevenir a deterioração aeróbia nas silagens tratadas no momento da ensilagem, por inibir o crescimento de fungos e, conseqüentemente, reduzir o aquecimento da massa de forragem ensilada (Pitt, 1990).

Os objetivos neste estudo foram determinar os efeitos do emurchecimento e do uso de aditivos (bacterianoenzimático ou ácido propiônico tamponado) na ensilagem do capim-tifton 85 (Cynodon sp.) sobre as características de fermentação e a composição químico-bromatológica da silagem produzida.

\section{Material e Métodos}

O experimento foi conduzido na Fazenda Água Comprida (Água Comprida/MG), localizada nas coordenadas $19^{\circ}$ $56^{\prime} 45^{\prime \prime}$ de latitude sul e $48^{\circ} 02^{\prime} 15^{\prime \prime}$ de longitude oeste. Os solos da região são de textura muito argilosa, Latossolo Roxo Distrófico (Prado, 1997), e o clima pode ser classificado como Aw, isto é, tropical úmido (verão chuvoso e inverno seco), segundo o sistema de Köppen. A região apresenta precipitação média anual de 1.200 a $1.500 \mathrm{~mm}$ e temperaturas médias de 21 a $22^{\circ} \mathrm{C}$ (Prado, 1997).

A área escolhida para colheita da forragem e confecção das silagens foi uma gleba destinada à produção de feno, estabelecida em 1996 com capim-tifton 85 (Cynodon $\mathrm{sp}$.). A área foi previamente fertilizada com $358 \mathrm{~kg} / \mathrm{ha}$ da fórmula 30-00-20 (N-P-K) logo após o último corte que antecedeu o ensaio e recebeu fertilização corretiva anual para apresentar 30 ppm de fósforo, $75 \%$ de saturação por bases e nível de potássio em torno de $5 \%$ da capacidade de troca catiônica.

As silagens foram confeccionadas entre os dias 15 e 21 de fevereiro de 2000. As condições climáticas predominantes nesses dias foram satisfatórias, com temperatura média de $26,5^{\circ} \mathrm{C}$ e umidade relativa do ar em torno de $73 \%$. A forragem foi colhida com idade fisiológica equivalente a 35 dias de crescimento vegetativo. O material foi ceifado com 
uma segadora condicionadora, marca CASE, modelo 8850 HP, equipada com condicionador de rolos de metal. O material foi submetido ao emurchecimento visando obter teores crescentes de matéria seca na ensilagem. O teor de matéria seca do material exposto no campo foi monitorado por meio de mensurações do teor de umidade utilizando-se forno de microondas (Pastorini et al., 2002). Quando o teor de matéria seca foi alcançado, o material foi picado em partículas de aproximadamente $8 \mathrm{~cm}$ e enfardado em forma cúbica $(140 \mathrm{~cm}$ comprimento $\mathrm{x} 120 \mathrm{~cm}$ de largura $\mathrm{x} 70 \mathrm{~cm}$ de altura), mediante o uso de enfardadora, marca CLAAS, modelo Quadrant $1200 \mathrm{RC}$. Imediatamente, os fardos foram envolvidos automaticamente (embaladora, marca REKORD, modelo Q-Pack 120) com seis camadas de filme plástico (TRIOPLAST AB, modelo Triowrap, $75 \mathrm{~cm}$ x 0,0025 cm) com $50 \%$ de sobreposição.

Os tratamentos consistiram de cinco silagens (200-300, 300-400, 400-500, 500-600 e 600-700 g/kg MS), confeccionadas sem (SA) aditivo bacteriano-enzimático comercial (SilAll - ALLTECH INC.) (ABE); três com aplicação (CA) de teores baixo, médio e alto (200-300, 400-500 e 600-700 g/kg MS, respectivamente) de ABE; e uma com alto teor de matéria seca, obtido por emurchecimento da forragem $(600-700 \mathrm{~g} / \mathrm{kg}$ MS), que foi pulverizada externamente com $0,011 \mathrm{~mL} / \mathrm{cm}^{2}$ de ácido propiônico tamponado (APT), antes do revestimento com filme plástico. Portanto, os tratamentos foram constituídos de distintas concentrações de MS, sem ou com aditivo bacteriano-enzimático (SA e CA, respectivamente)(250SA, 350SA, 450SA, 550SA, 650SA, 250CA, 450CA, 650CA e 650APT). As amostras foram colhidas à zero hora antes da ensilagem e 6, 12 horas, 1, 2, 4, 8, 16,32,90 e 180 dias após a ensilagem, para se estabelecer a tendência das características de fermentação e composição química.

$\mathrm{O}$ aditivo utilizado apresentou os seguintes níveis de garantia declarados: $1,0 \times 10^{9}$ unidades formadoras de colônias (UFC) de Streptococcus faecium $/ \mathrm{g} ; 1,0 \times 10^{9} \mathrm{UFC}$ de Lactobacillus plantarum $/ \mathrm{g} ; 1,0 \times 10^{8}$ UFC de Pediococcus acidilactici/g e as enzimas hemicelulase, celulase e amilase. Dois litros e meio de solução a $5 \mathrm{~g} / \mathrm{L}$ foram aplicados por tonelada de forragem, segundo recomendações do fabricante. Essa solução foi aspergida utilizando-se um sistema de bomba de diafragma ligada a dois bicos aspersores acoplados à plataforma de recolhimento da enfardadora imediatamente antes do enfardamento da forragem.

Os fardos foram amostrados empregando-se um amostrador do tipo "core sampler" (50 cm de comprimento x $6 \mathrm{~cm}$ diâmetro) acoplado a uma motosserra. Amostras foram tomadas nos tempos pré-estabelecidos antes e após o revestimento dos fardos com filme plástico. Também foram coletadas amostras da forragem que deu origem a cada tratamento no momento da ceifa do material. Os dados obtidos foram utilizados como covariável para a avaliação da evolução temporal dos tratamentos. Aos 90 e 180 dias não foram amostradas as silagens 350SA, 250CA e 650APT.

A temperatura interna do fardo $\left({ }^{\circ} \mathrm{C}\right)$ foi tomada no momento da amostragem, utilizando-se um termômetro de bulbo mercúrio, colocado $\left({ }^{\circ} \mathrm{C}\right)$ com o auxílio de uma sonda na porção superior de cada fardo.

A leitura do $\mathrm{pH}$ do extrato aquoso foi tomada de acordo com o procedimento descrito a seguir: uma fração de $25 \mathrm{~g}$ de amostra foi misturada a $450 \mathrm{~mL}$ de água deionizada, para obtenção de um extrato aquoso, do qual foi realizada a leitura do $\mathrm{pH}$ com o uso de um peagâmetro. Amostras do material original (ceifa) e dos fardos foram utilizadas para determinação do teor de matéria seca (TMS) e do poder tampão (PT), segundo metodologia descrita por Playne \& McDonald (1966), além dos teores de proteína bruta (PB), extrato etéreo (EE) (AOAC, 1984) e N-NH $\mathrm{N}_{3}(\mathrm{~g} / \mathrm{kg} \mathrm{N})$ (Chaney $\&$ Marbach, 1962). O TMS foi determinado pela secagem da amostra em estufa de circulação forçada a $55^{\circ} \mathrm{C}$, seguida de correção a $105^{\circ} \mathrm{C}$.

As frações fibra em detergente neutro (FDN), fibra em detergente ácido (FDA) e lignina foram avaliadas segundo o método seqüencial de determinação da fração fibrosa descrito por Holden (1999), utilizando-se o equipamento ANKON (ANKON Technology, INC). As frações nitrogênio insolúvel em detergente neutro (NIDN) e nitrogênio insolúvel em detergente ácido (NIDA) foram estimadas de acordo com Krishnamoorth et al. (1982) e com a concentração de nutrientes digestíveis totais (NDT), segundo a equação descrita por Weiss et al. (1992), ajustada pelo NRC (2001).

O delineamento experimental utilizado foi inteiramente casualizado, com três repetições, arranjadas em esquema fatorial $5 \times 2$ incompleto, em parcelas subdivididas no tempo, sendo os tratamentos os fatores das parcelas e o tempo, as subparcelas. Além dos fatores, foram incorporadas ao modelo duas co-variáveis: uma correspondente à composição original da forragem (ceifa) e outra ao teor de matéria seca original obtida nos fardos amostrados.

O modelo proposto foi analisado pelo PROC GLM do SAS (SAS, 1988) e os valores médios foram estimados pelo LSMEANS do mesmo sistema. Para comparações específicas de grupos de tratamentos, aplicou-se o teste F para contrastes, a partir do desdobramento dos graus de liberdade. Os objetivos foram comparar os tratamentos com e sem aditivos e o tratamento 650APT àqueles com mesmo teor de matéria seca, sem (650SA) e com (650CA) aditivo bacteriano-enzimático, e verificar quais apresentaram maiores benefícios com o uso dos aditivos avaliados. 


\section{Resultados e Discussão}

$\mathrm{O} \mathrm{pH}$ foi influenciado pelo conteúdo de matéria seca das silagens, apresentando declínio mais acentuado e menores valores finais nas silagens com 250 a $550 \mathrm{~g} / \mathrm{kg} \mathrm{MS}$ (Tabela 1).

No maior teor de matéria seca, tanto na silagem sem aditivo bacteriano-enzimático (650SA) como na tratada com ácido propiônico tamponado (650APT), o pH permaneceu praticamente inalterado. $\mathrm{O}$ emurchecimento determinou menor intensidade do processo de fermentação, traduzido pelo aumento do $\mathrm{pH}$, com o incremento do conteúdo de MS da forragem ensilada, corroborando os relatos encontrados na literatura (Wyss, 1999; Evangelista et al., 2000). Segundo relatos de McDonald et al., (1991), o aumento do $\mathrm{pH}$ ocorre porque o incremento do teor de matéria seca tem efeito direto sobre a contagem total de bactérias láticas e a taxa de fermentação.
Nos tratamentos com 450 e $550 \mathrm{~g} / \mathrm{kg}$ MS, foram observadas condições favoráveis para o declínio do $\mathrm{pH}$ (Tabela 1). Pela análise de contrastes, o uso de ABE (CA) favoreceu a redução do $\mathrm{pH}$ apenas nas silagens com médio e alto teores de matéria seca ( 450 e $650 \mathrm{~g} / \mathrm{kg} \mathrm{MS}$ ) amostradas aos 4 e 90 dias após a ensilagem $(\mathrm{P}<0,05)$. O uso de ácido propiônico tamponado não alterou o $\mathrm{pH}(\mathrm{P}>0,05)$ em relação ao tratamento 650SA em nenhum dos tempos de estocagem avaliados. Entretanto, o pH se elevou $(\mathrm{P}<0,05)$ no tratamento $650 \mathrm{CA}$ à zero hora antes da ensilagem e aos 4 e 32 dias de estocagem.

O efeito do uso de aditivo bacteriano-enzimático (CA) sobre o $\mathrm{pH}$ das silagens está de acordo com a literatura, que aponta a efetividade deste tipo de aditivo em reduzir o $\mathrm{pH}$ somente quando associado ao adequado teor de matéria seca da forragem ensilada. Neste estudo, o CA foi efetivo nos teores de matéria seca médio e alto. O'Kiely et al. (1999) não observaram efeitos positivos de aditivos sobre o $\mathrm{pH}$ quando

Tabela 1 - Médias dos valores de pH de silagens do capim-tifton 85 submetidas ao emurchecimento e à presença (CA) ou não (SA) de aditivo bacteriano-enzimático ou ácido propiônico tamponado (APT)

Table 1 - Mean values of $\mathrm{pH}$ from Tifton 85 grass silages submitted to wilting and presence (WA) or not (WoA) of bacterial-enzymatic additive or buffered propionic acid (BPA)

\begin{tabular}{|c|c|c|c|c|c|c|c|c|c|c|c|}
\hline \multirow{2}{*}{$\begin{array}{l}\text { Teor de MS } \\
\text { Dry matter content } \\
\mathrm{g} / \mathrm{kg} \mathrm{MS}(\mathrm{g} / \mathrm{kg} D M)\end{array}$} & \multicolumn{11}{|c|}{$\begin{array}{c}\text { Momento de amostragem (horas e dias) } \\
\text { Sampling time (hours and days) }\end{array}$} \\
\hline & $0 \mathrm{~h}$ & $6 \mathrm{~h}$ & $12 \mathrm{~h}$ & $24 \mathrm{~h}$ & $2 d$ & $4 \mathrm{~d}$ & $8 \mathrm{~d}$ & $16 \mathrm{~d}$ & $32 \mathrm{~d}$ & $90 \mathrm{~d}$ & $180 \mathrm{~d}$ \\
\hline & \multicolumn{11}{|c|}{$\mathrm{pH}$} \\
\hline & \multicolumn{11}{|c|}{$\begin{array}{l}\text { Sem aditivo bacteriano-enzimático } \\
\text { Without bacterial-enzymatic additive }\end{array}$} \\
\hline 250 & $6,16 d^{1}$ & $6,15 b$ & $6,15 b$ & $6,00 \mathrm{~b}$ & $5,89 \mathrm{~b}$ & $5,69 \mathrm{~d}$ & $5,55 \mathrm{~d}$ & $5,45 \mathrm{de}$ & $5,23 \mathrm{bc}$ & $4,84 \mathrm{c}$ & $4,72 \mathrm{c}$ \\
\hline 350 & $6,31 \mathrm{c}$ & $6,23 \mathrm{ab}$ & $6,42 \mathrm{ab}$ & $6,36 \mathrm{a}$ & $6,06 \mathrm{ab}$ & $6,10 \mathrm{c}$ & $5,66 \mathrm{~cd}$ & $5,37 \mathrm{de}$ & $5,18 \mathrm{bc}$ & $\mathrm{ND}^{2}$ & ND \\
\hline 450 & $6,42 \mathrm{abc}$ & $6,46 a$ & $6,46 a$ & $6,46 \mathrm{a}$ & $6,46 \mathrm{a}$ & $6,4 \mathrm{a}$ & $6,12 \mathrm{ab}$ & $5,77 \mathrm{cde}$ & $5,49 \mathrm{~b}$ & $5,18 \mathrm{c}$ & $5,03 \mathrm{bc}$ \\
\hline 550 & $6,33 b c$ & $6,54 a$ & $6,54 \mathrm{a}$ & $6,48 \mathrm{a}$ & $6,39 \mathrm{ab}$ & $6,42 \mathrm{a}$ & $6,02 \mathrm{abc}$ & $5,77 \mathrm{cde}$ & $5,43 \mathrm{bc}$ & $5,18 \mathrm{c}$ & $5,23 b c$ \\
\hline 650 & $6,45 \mathrm{ab}$ & $6,39 \mathrm{ab}$ & $6,39 \mathrm{ab}$ & $6,43 \mathrm{a}$ & $6,45 \mathrm{a}$ & $6,39 \mathrm{ab}$ & $6,26 a b$ & $6,32 \mathrm{a}$ & $6,27 \mathrm{a}$ & $6,40 \mathrm{a}$ & $6,20 \mathrm{a}$ \\
\hline \multicolumn{12}{|c|}{$\begin{array}{l}\text { Com aditivo bacteriano-enzimático } \\
\text { With bacterial-enzymatic additive }\end{array}$} \\
\hline 250 & $6,13 d$ & $6,37 \mathrm{ab}$ & $6,37 \mathrm{~b}$ & $6,19 a b$ & $6,23 \mathrm{ab}$ & $6,03 \mathrm{c}$ & $5,90 \mathrm{bcd}$ & $5,82 \mathrm{bcd}$ & $5,37 \mathrm{bc}$ & ND & ND \\
\hline 450 & $6,49 a$ & $6,52 \mathrm{a}$ & $6,52 \mathrm{a}$ & $6,45 \mathrm{a}$ & $6,22 \mathrm{ab}$ & $5,91 \mathrm{~cd}$ & $5,62 \mathrm{~d}$ & $5,32 \mathrm{e}$ & $5,07 \mathrm{c}$ & $4,91 \mathrm{c}$ & $4,94 b c$ \\
\hline 650 & $6,31 b c$ & $6,49 a$ & $6,49 \mathrm{a}$ & $6,40 \mathrm{a}$ & $6,36 \mathrm{ab}$ & $6,15 \mathrm{abc}$ & $6,37 \mathrm{a}$ & $6,13 a b c$ & $5,91 \mathrm{a}$ & $5,78 \mathrm{ab}$ & $5,56 \mathrm{ab}$ \\
\hline
\end{tabular}

Com aplicação externa de ácido propiônico tamponado With buffered propionic acid application

\begin{tabular}{|c|c|c|c|c|c|c|c|c|c|c|c|}
\hline $\begin{array}{l}650 \\
\text { Contrastes (Contrast) }\end{array}$ & $6,41 \mathrm{abc}$ & $6,37 \mathrm{ab}$ & $6,37 \mathrm{ab}$ & $6,41 \mathrm{a}$ & $6,39 \mathrm{ab}$ & $6,37 \mathrm{ab}$ & $6,28 \mathrm{a}$ & $6,28 \mathrm{ab}$ & $6,22 \mathrm{a}$ & ND & ND \\
\hline $\mathrm{SA} \times \mathrm{CA}(W o A x W A)$ & $\mathrm{ns}^{3}$ & ns & ns & ns & ns & $*$ & ns & ns & ns & $*$ & ns \\
\hline 650APT $\times$ 650SA $(650 B P A \times 650 \mathrm{WoA})$ & ns & ns & ns & ns & ns & ns & ns & ns & ns & ND & ND \\
\hline 650APT $\mathrm{x}$ 650CA $(650 B P A \times 650 \mathrm{WA})$ & $* 4$ & ns & ns & ns & ns & $*$ & ns & ns & $*$ & ND & ND \\
\hline
\end{tabular}

1 Médias seguidas de letras iguais na mesma coluna não diferem $(P>0,05)$ pelo LSmeans.

$2 \mathrm{ND}=$ não determinado.

3 ns = não-significativo $(P>0,05)$ pela análise de contrastes.

$4 *$ Significativo $(P<0,05)$ pela análise de contrastes.

1 Means followed by same letters in the same column do not differ $(P>0.05)$ by LSmeans.

$2 N D=$ not determinated.

3 ns $=$ not significant $(P>0.05)$ by contrasts analysis

4* Significant $(P<0.05)$ by contrasts analysis.

APT - Ácido propiônico tamponado (BPA-Buffered propionic acid).

CA - Com aditivo bacteriano-enzimático (WA - With bacterial-enzymatic additive).

SA - Sem aditivo bacteriano-enzimático (WoA -Without bacterial-enzymatic additive). 
aplicados em condições desfavoráveis, ou seja, alto teor de umidade, baixa concentração de carboidratos solúveis e alto poder tampão. Mühlbach (2000) destacou que, na Europa e nos Estados Unidos, os aditivos bacterianos são usados principalmente em associação à forragem emurchecida contendo teores superiores a $300 \mathrm{~g} / \mathrm{kg}$ de MS.

$\mathrm{O}$ incremento do teor de MS reduziu $(\mathrm{P}<0,05)$ o poder tampão (PT) às 12 horas e aos 8 e 180 dias de estocagem (Tabela 2). Estes menores valores de PT são esperados em silagens emurchecidas, visto que o processo de desidratação a que se submete a forragem normalmente destrói ácidos orgânicos fracos, co-responsáveis pelo poder tampão (McDonald et al., 1991). Os dados da literatura, quanto aos efeitos do emurchecimento sobre o PT, são conflitantes. Berto \& Mühlbach (1997) verificaram redução no PT com o incremento do teor de MS da aveia preta, enquanto Tosi et al. (1995) observaram aumento com o emurchecimento do capim-elefante. O efeito do emurchecimento sobre o PT parece estar associado à espécie vegetal e aos teores de MS inicial e final. Pela análise dos contrastes estabelecidos, o uso de ABE $(\mathrm{CA})$ elevou $(\mathrm{P}<0,05)$ o PT aos 4 e 180 dias de estocagem para os teores baixo e médio de matéria seca e reduziu $(\mathrm{P}<0,05)$ o $\mathrm{PT}$ no maior teor de MS nos mesmos tempos de estocagem. O uso de APT não alterou $(\mathrm{P}>0,05)$ o $\mathrm{PT}$ das silagens 650SA e 650CA durante todo o período avaliado.

Os tratamentos com maior teor de matéria seca $(650 \mathrm{~g} / \mathrm{kg}$ MS, SA e com APT) apresentaram maiores valores de temperatura, provavelmente em razão da maior aeração da massa, estando de acordo com os relatos de McDonald et al. (1991). O uso de ABE foi efetivo $(\mathrm{P}<0,05)$ em reduzir a temperatura interna das 12 horas até os 8 dias de estocagem, quando não houve mais efeito $(\mathrm{P}>0,05)$ dos tratamentos sobre esse parâmetro (Tabela 3). O uso de APT não alterou

Tabela 2 - Médias dos valores do poder tampão (PT) de silagens do capim-tifton 85 submetidas ao emurchecimento e à presença (CA) ou não (SA) de aditivo bacteriano-enzimático ou ácido propiônico tamponado (APT)

Table 2 - Mean values of buffering capacity from Tifton 85 grass silages submitted to wilting and presence (WA) or not (WoA) bacterial-enzymatic additive (BEA) or buffered propionic acid (BPA)

\begin{tabular}{|c|c|c|c|c|c|c|c|c|c|c|c|}
\hline \multirow{2}{*}{$\begin{array}{l}\text { Teor de MS } \\
\text { Dry matter content } \\
\mathrm{g} / \mathrm{kg} \mathrm{MS}(\mathrm{g} / \mathrm{kg} D M)\end{array}$} & \multicolumn{11}{|c|}{$\begin{array}{c}\text { Momento de amostragem (horas e dias) } \\
\text { Sampling time (hours and days) }\end{array}$} \\
\hline & $0 \mathrm{~h}$ & $6 \mathrm{~h}$ & $12 \mathrm{~h}$ & $24 \mathrm{~h}$ & $2 \mathrm{~d}$ & $4 \mathrm{~d}$ & $8 \mathrm{~d}$ & $16 \mathrm{~d}$ & $32 \mathrm{~d}$ & $90 \mathrm{~d}$ & $180 \mathrm{~d}$ \\
\hline & \multicolumn{11}{|c|}{$\begin{array}{l}\text { Sem aditivo bacteriano-enzimático } \\
\text { Without bacterial-enzymatic additive }\end{array}$} \\
\hline & \multicolumn{11}{|c|}{$\begin{array}{l}\text { Com aditivo bacteriano-enzimático } \\
\text { With bacterial-enzymatic additive }\end{array}$} \\
\hline & \multicolumn{11}{|c|}{$\begin{array}{c}\text { Com aplicação externa de ácido propiônico tamponado } \\
\text { With buffered propionic acid application }\end{array}$} \\
\hline 650 & $180 \mathrm{a}$ & $159 \mathrm{a}$ & $113 \mathrm{ab}$ & $195 \mathrm{a}$ & $203 a$ & $151 \mathrm{a}$ & $183 b$ & $368 \mathrm{a}$ & $257 \mathrm{abc}$ & ND & ND \\
\hline \multicolumn{12}{|l|}{ Contraste } \\
\hline $\mathrm{SA} \times \mathrm{CA}(W o A \times W A)$ & $\mathrm{ns}^{3}$ & $\mathrm{~ns}$ & ns & ns & ns & $* 4$ & ns & Ns & ns & ns & * \\
\hline $650 \mathrm{APT} \times 650 \mathrm{SA}(650 \mathrm{BPA} \times 650 \mathrm{WoA})$ & ns & ns & ns & ns & ns & ns & ns & Ns & ns & ND & ND \\
\hline 650APT $\times$ 650CA $(650 B P A \times 650 W A)$ & ns & ns & ns & ns & ns & ns & ns & Ns & ns & ND & ND \\
\hline
\end{tabular}

1 Médias seguidas de letras iguais na mesma coluna não diferem $(P>0,05)$ pelo LSmeans.

$2 \mathrm{ND}=$ não determinado.

3 ns $=$ não-significativo $(P>0,05)$ pela análise de contrastes.

${ }^{4 *}$ Significativo $(P<0,05)$ pela análise de contrastes.

1 Means followed by same letters in the same column do not differ $(P>0.05)$ by LSmeans.

$2 N D=$ not determinated.

3 ns $=$ not significant $(P>0.05)$ by contrasts analysis.

4* Significant $(P<0.05)$ by contrasts analysis.

APT - Ácido propiônico tamponado (BPA-Buffered propionic acid).

CA - Com aditivo bacteriano-enzimático (WA - With bacterial-enzymatic additive)

SA - Sem aditivo bacteriano-enzimático (WOA -Without bacterial-enzymatic additive). 
$(\mathrm{P}>0,05)$ a temperatura interna em relação ao tratamento 650SA, mas elevou $(\mathrm{P}<0,05)$ este parâmetro em relação ao tratamento 650CA, às 12 horas e aos 1,2 e 8 dias de estocagem. Portanto, o uso de APT não proporcionou o efeito esperado de redução na temperatura da massa, talvez porque a aplicação foi feita apenas na superfície externa do fardo, como evidenciado por Pitt (1990).

$\mathrm{O}$ teor de FDN decresceu $(\mathrm{P}<0,05)$ com o aumento do conteúdo de matéria seca das silagens, à zero hora antes da ensilagem e 16 dias após, mas esse parâmetro sofreu acréscimo $(\mathrm{P}<0,05)$ com o incremento do conteúdo de MS aos 8 e 32 dias. Aos 90 e 180 dias de estocagem não houve diferença significativa $(\mathrm{P}>0,05)$ entre os tratamentos (Tabela 4). Evangelista et al. (2000) verificaram redução da FDN com o aumento do conteúdo de MS do capim-grama estrela roxa (Cynodon nlemfuensis) ensilado. Os valores observados por esses autores foram superiores aos deste estudo. O uso de ABE elevou ( $\mathrm{P}<0,05)$ o teor de FDN aos 8 dias pós-ensilagem, não sendo efetivo $(\mathrm{P}>0,05)$ nos demais tempos de estocagem. $\mathrm{O}$ uso de APT não alterou $(\mathrm{P}>0,05)$ o conteúdo de FDN das silagens. Berto \& Mühlbach (1997) não observaram efeito do emurchecimento e uso de $\mathrm{ABE}$ sobre o conteúdo de FDN de silagem de aveia preta.

O emurchecimento e o uso de $\mathrm{ABE}$ não alteraram $(\mathrm{P}>0,05)$ o conteúdo de FDA das silagens (Tabela 4). Os resultados obtidos neste estudo estão de acordo com os reportados por Evangelista et al. (2000), que não notaram variação decorrente do emurchecimento nos teores FDA das silagens de capim-grama estrela, porém verificaram menores valores que deste ensaio. Henrique \& Bose (1992) não observaram variação nos teores de FDN e FDA com o uso de ABE na silagem de capim-elefante, mas os valores obtidos foram próximos aos verificados neste estudo. O uso de APT reduziu $(\mathrm{P}<0,05)$ a concentração de FDA da silagem 650SA aos 16 dias, mas não teve efeito $(\mathrm{P}>0,05)$ nos demais tempos de estocagem.

Tabela 3 - Médias dos valores de temperatura $\left({ }^{\circ} \mathrm{C}\right)$ de silagens de capim-tifton 85 submetidas ao emurchecimento e à presença $(\mathrm{CA})$ ou não (SA) de aditivo bacteriano-enzimático e ácido propiônico tamponado (APT)

Table 3 - $\quad$ Mean values of temperature $\left({ }^{\circ} \mathrm{C}\right)$ from Tifton 85 grass silages submitted to wilting and presence (WA) or not (WoA) bacterial-enzymatic additive (BEA) or buffered propionic acid (BPA)

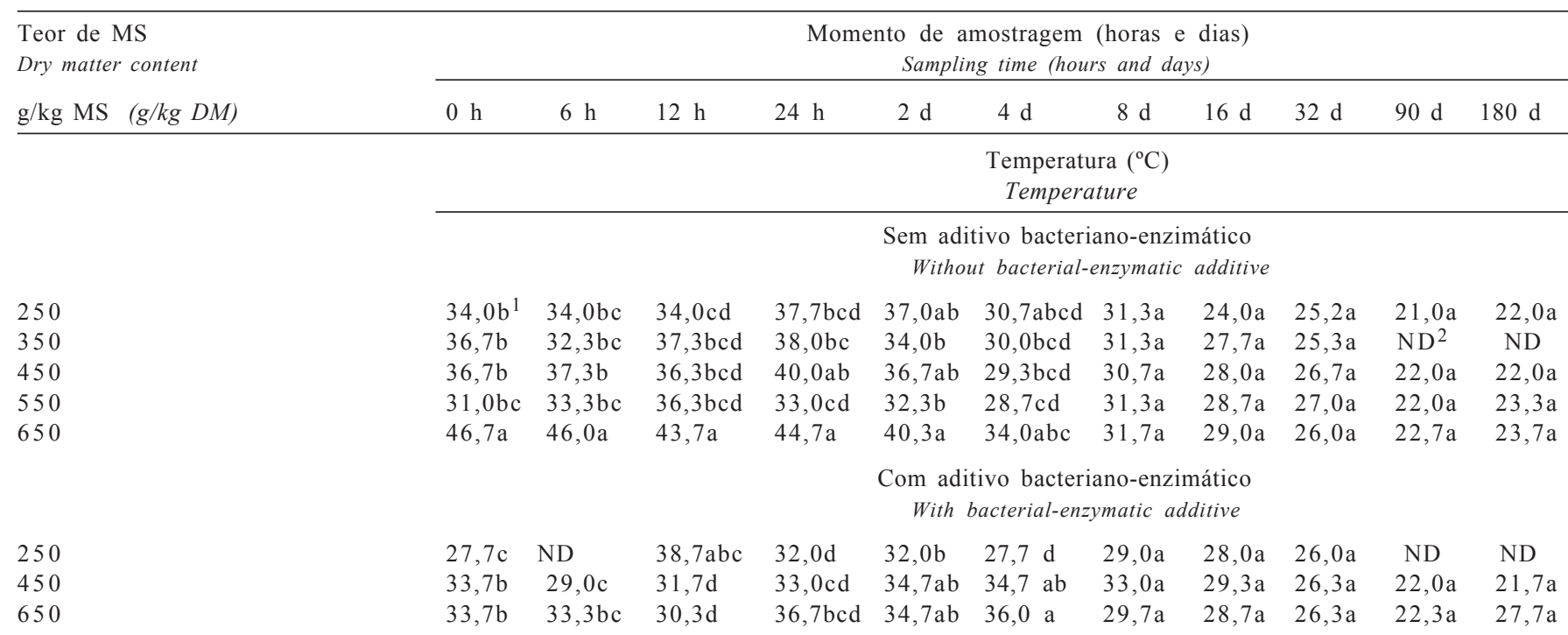

Com aplicação externa de ácido propiônico tamponado With buffered propionic acid application

650

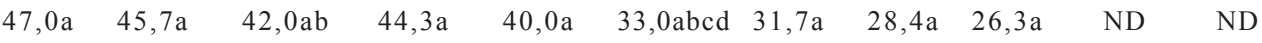

Contrastes (Contrast)

$\mathrm{SA} \times \mathrm{CA}($ WoA $x W A)$

650APT $x$ 650SA $(650 B P A \times 650 \mathrm{WOA}) \quad \mathrm{ns}^{4}$

$650 \mathrm{APT} \times 650 \mathrm{CA}(650 \mathrm{BPA} \times 650 \mathrm{WA}) \mathrm{ns}$

$* 3 \quad$ ns $*$

1 Médias seguidas de letras iguais na mesma coluna não diferem $(P>0,05)$ pelo LSmeans.

$2 \mathrm{ND}=$ não determinado.

$3 \mathrm{~ns}=$ não-significativo $(\mathrm{P}>0,05)$ pela análise de contrastes.

${ }^{4 *}$ Significativo $(P<0,05)$ pela análise de contrastes.

1 Means followed by same letters in the same column do not differ $(P>0.05)$ by LSmeans.

${ }^{2} N D=$ not determinated.

$3 n s=$ not significant $(P>0.05)$ by contrasts analysis.

${ }^{4 *}$ Significant $(P<0.05)$ by contrasts analysis.

APT - Ácido propiônico tamponado (BPA-Buffered propionic acid).

CA - Com aditivo bacteriano-enzimático (WA - With bacterial-enzymatic additive).

SA - Sem aditivo bacteriano-enzimático (WoA -Without bacterial-enzymatic additive). 


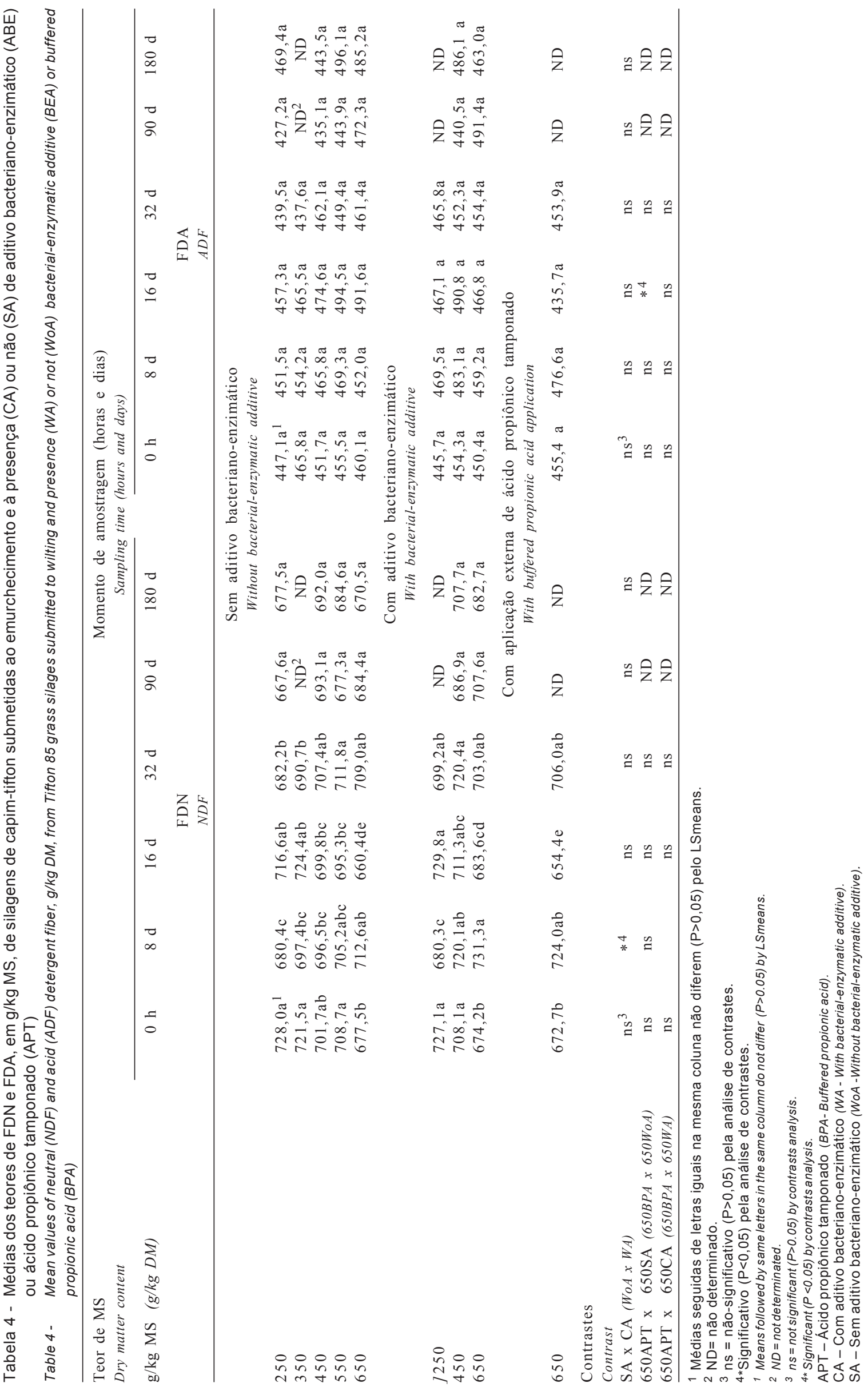


O uso de $\mathrm{ABE}$ tem como finalidade aumentar a disponibilidade de substrato para as bactérias produtoras de ácido lático, pela degradação de carboidratos complexos em carboidratos solúveis, e reduzir o conteúdo de fibra da forragem (Muck \& Kung, 1997). Não foi constatado o efeito desse aditivo sobre a redução dos teores de FDN e FDA (Tabela 4). Magalhães \& Rodrigues (2004), avaliando silagem de alfafa emurchecida associada a inoculante bacteriano, não constataram redução nos teores de FDN, FDA, LDA, hemicelulose e celulose e alegaram que esses resultados talvez estejam ligados à ausência de efeito sobre o $\mathrm{pH}$ da silagem.

O emurchecimento elevou $(\mathrm{P}<0,05)$ o teor de lignina $(\mathrm{LIG})$ à zero hora antes da ensilagem e aos 16 e 90 dias de estocagem (Tabela 5), como observado por Berto \& Mülhbach (1997), que também observaram efeito negativo do emurchecimento sobre o teor de LIG na silagem de aveia preta. Este resultado, no entanto, contraria os obtidos por
Crestana et al. (2001), que não relataram alteração no teor de LIG com o emurchecimento do capim-tanzânia. O uso de ABE reduziu $(\mathrm{P}<0,05)$ o conteúdo de LIG das silagens apenas na avaliação aos 16 dias de estocagem, não havendo efeito significativo para o teor de lignina $(\mathrm{P}>0,05)$ nos demais tempos de estocagem. Coan et al. (2001) não observaram alteração no conteúdo de LIG com o uso de ABE em silagens dos capins-tanzânia e mombaça. O uso de APT reduziu $(\mathrm{P}<0,05)$ o teor de LIG aos 16 dias em relação ao tratamento $650 \mathrm{SA}$ e aumentou $(\mathrm{P}<0,05)$ aos 8 dias em relação ao tratamento $650 \mathrm{CA}$.

Houve efeito significativo de tratamento $(\mathrm{P}<0,05)$ sobre o conteúdo de $\mathrm{PB}$, porém a interação tratamento $\mathrm{x}$ tempo de estocagem não foi significativa ( $\mathrm{P}>0,05)$, motivo pelo qual calculou-se a média geral por tratamento (Tabela 6). O conteúdo de $\mathrm{PB}$ das silagens foi influenciado pelo emurchecimento, registrando-se incremento $(\mathrm{P}<0,05)$ nesse

Tabela 5 - Médias dos teores de lignina de silagens de capim-tifton 85 submetidas ao emurchecimento e à presença (CA) ou não (SA) de aditivo bacteriano-enzimático ou ácido propiônico tamponado (APT)

Table 5 - Mean values of lignin content from Tifton 85 grass silages submitted to wilting and presence (WA) or not (WoA) bacterial-enzymatic additive (BEA) or buffered propionic acid (BPA)

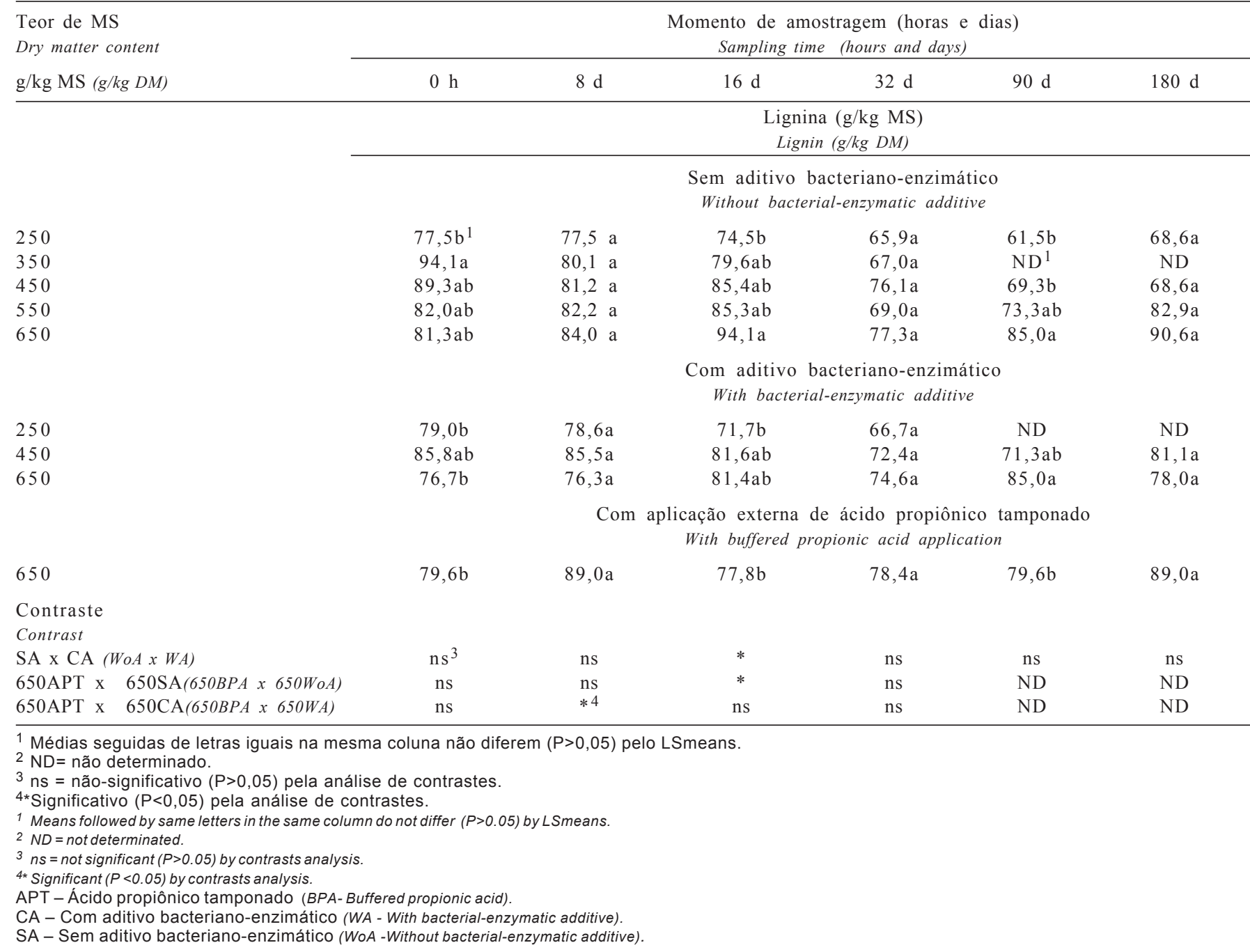




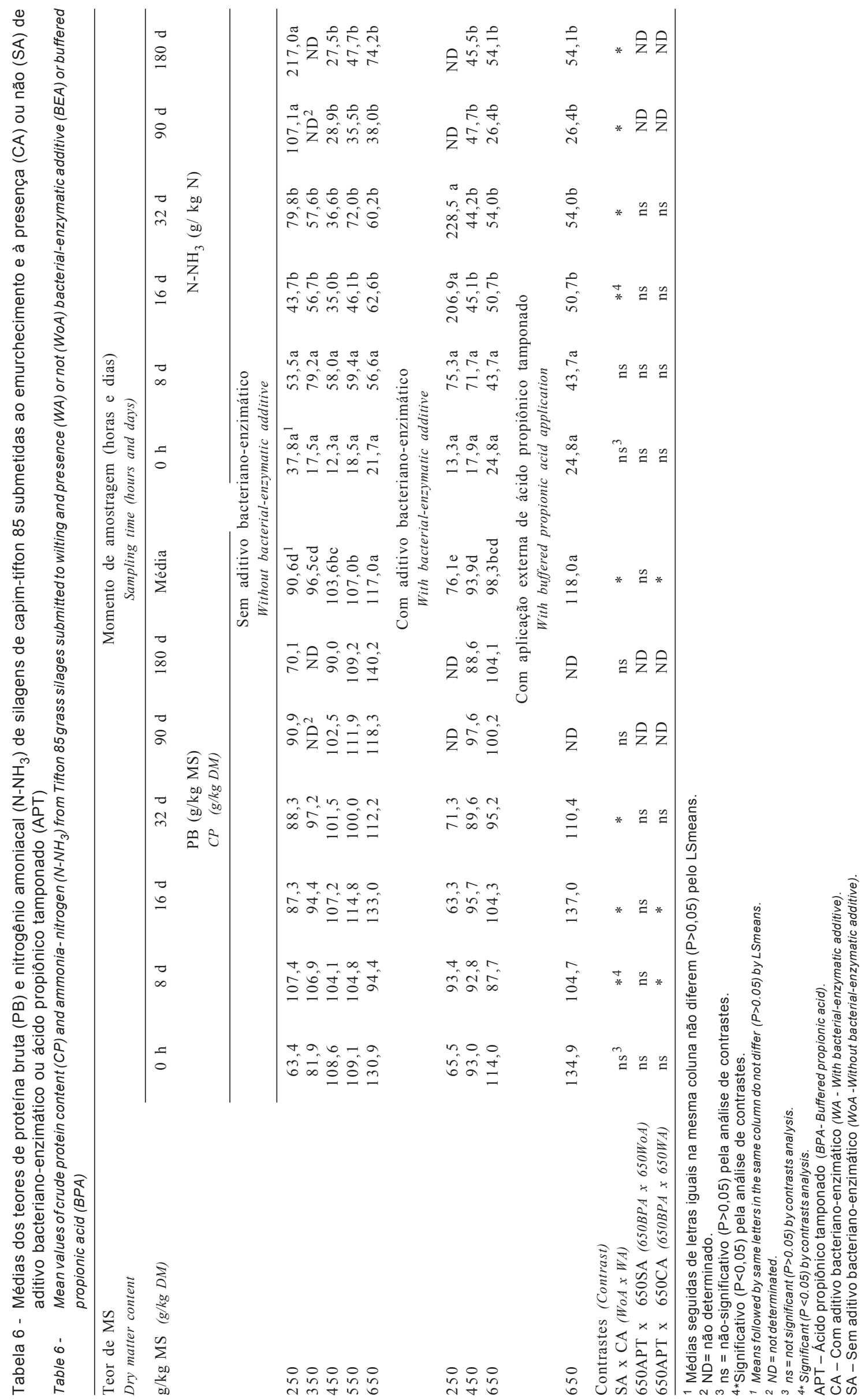




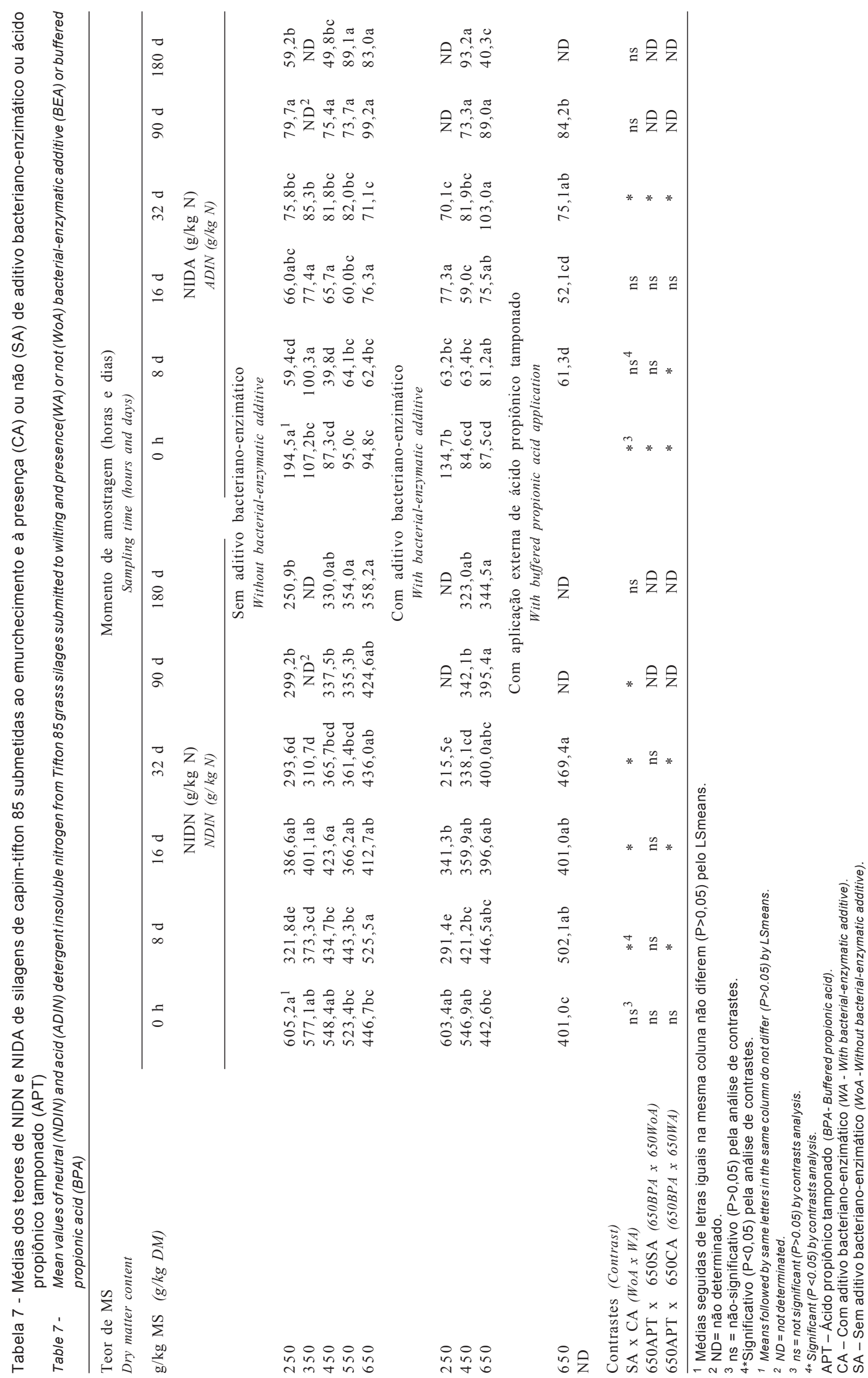


parâmetro com o aumento do conteúdo de matéria seca da silagem. Esse comportamento provavelmente está associado à redução na concentração de carboidratos solúveis durante o emurchecimento, proporcionando aumento no teor de PB, e ao aumento no teor de MS, que geralmente provoca redução na proteólise (McDonald, 1991). Tosi et al.(1995)e Evangelista et al. (2000) não observaram efeito do emurchecimento sobre o conteúdo de $\mathrm{PB}$ de gramíneas tropicais. As silagens tratadas com $\mathrm{ABE}$ apresentaram menores $(\mathrm{P}<0,05)$ teores de $\mathrm{PB}$ em todos os níveis de MS avaliados. Berto \& Mühlbach (1997) observaram efeito positivo do emurchecimento sobre o teor de $\mathrm{PB}$, embora o uso de $\mathrm{ABE}$ não tenha alterado esse parâmetro na silagem de aveia preta.

$\mathrm{O}$ tratamento com APT não diferiu $(\mathrm{P}>0,05)$ do 650SA, mas elevou $(\mathrm{P}<0,05)$ o teor de $\mathrm{PB}$ nas avaliações aos 8 e 16 dias e na média geral, em relação ao tratamento 650CA.

A concentração de $\mathrm{N}^{-\mathrm{NH}_{3}}$ elevou com o tempo de estocagem no menor teor de MS (Tabela 6). Os maiores $(\mathrm{P}<0,05)$ valores de $\mathrm{N}-\mathrm{NH}_{3}$ nas silagens com menor conteúdo de MS (250 g/kg MS), sem e com ABE, demonstraram haver proteólise intensa nas forragens mais úmidas. Tosi et al. (1995) e Wyss (1999), no entanto, observaram redução no conteúdo de nitrogênio amoniacal $\left(\mathrm{N}-\mathrm{NH}_{3}\right)$ com o aumento do conteúdo de MS da silagem. O uso de ABE aumentou $(\mathrm{P}<0,05)$ o teor de $\mathrm{N}-\mathrm{NH}_{3}$ nas forragens com baixo e médio conteúdos de MS ( 250 e $450 \mathrm{~g} / \mathrm{kg} \mathrm{MS})$ e reduziu $(\mathrm{P}<0,05)$ no teor mais elevado de matéria seca ( $650 \mathrm{~g} / \mathrm{kg} \mathrm{MS})$ aos 16 , 32, 90 e 180 dias de estocagem. O uso de APT não alterou $(\mathrm{P}>0,05)$ o teor de $\mathrm{N}-\mathrm{NH}_{3}$ em relação aos tratamentos 650SA e 650CA.

Henrique \& Bose (1992) não observaram variação nos teores de $\mathrm{PB}$ e $\mathrm{N}-\mathrm{NH}_{3}$ com o uso de $\mathrm{ABE}$ na ensilagem de capim-elefante e obtiveram valores superiores aos verificados neste estudo. Coan et al. (2001) não notaram alteração no teor de $\mathrm{N}-\mathrm{NH}_{3}$ com o uso de $\mathrm{ABE}$ em silagens dos capins tanzânia e mombaça, apesar da redução no teor de PB. Haigh et al. (1996) verificaram manutenção do teor de PB e redução do nitrogênio amoniacal com uso de aditivo bacteriano em silagem emurchecida e revestida com lona plástica. Esses autores sugeriram um limite de 80 a $100 \mathrm{~g} / \mathrm{kg} \mathrm{N}$ como critério para silagens adequadamente fermentadas. Os valores observados neste estudo estão abaixo desse limite, com exceção das silagens não emurchecidas, demonstrando que o emurchecimento foi efetivo em inibir a proteólise.

Verificou-se tendência de redução do nitrogênio insolúvel em detergente neutro (NIDN) ao longo do tempo (Tabela 7). O teor de NIDN revelou valores maiores $(\mathrm{P}<0,05)$ nas silagens com teores elevados de matéria seca, a partir da amostragem do oitavo dia, demonstrando menor atividade proteolítica nessas silagens. O uso de $\mathrm{ABE}$ reduziu $(\mathrm{P}<0,05)$ os teores de NIDN entre 8 e 90 dias, provavelmente em razão da ação das enzimas presentes no aditivo sobre o nitrogênio ligado à parede celular. $\mathrm{O}$ uso de $\mathrm{APT}$ não alterou $(\mathrm{P}>0,05) \mathrm{O}$ NIDN em relação ao tratamento 650SA, porém elevou $(\mathrm{P}<0,05)$ os valores de NIDN em relação ao tratamento 650CA.

$\mathrm{O}$ teor de NIDA foi superior $(\mathrm{P}<0,05)$ nas silagens com maiores conteúdos de matéria seca a partir da amostragem do oitavo dia (Tabela 7). A utilização do ABE reduziu $(\mathrm{P}<0,05)$ o teor de NIDA à zero hora antes da ensilagem $\mathrm{e}$ aumentou $(\mathrm{P}<0,05)$ aos 32 dias (Tabela 7). Berto \& Mühlbach (1997) observaram que o uso de ABE aumentou o NIDA e não alterou o NIDN, enquanto o pré-emurchecimento aumentou o NIDN e não alterou o NIDA, evidenciando que o emurchecimento reduziu a proteólise.

O efeito do emurchecimento sobre a proteólise resulta da menor concentração de água que impede a ação enzimática. Umaña et al. (1991) não observaram alteração no conteúdo de NIDA decorrente do pré-emurchecimento ou do uso de aditivo bacteriano durante a estocagem. A utilização do APT reduziu $(\mathrm{P}<0,05)$ o conteúdo de NIDA (Tabela 7) à zero hora antes da ensilagem em relação aos de 650SA e 650CA, mas aumentou aos 32 dias $(\mathrm{P}<0,05) \mathrm{em}$ relação ao tratamento $650 \mathrm{SA}$ e reduziu $(\mathrm{P}<0,05)$ em relação ao tratamento 650CA. Silagens com elevados teores de MS estão sujeitas à elevação da temperatura da massa ensilada, predispondo à ocorrência de reações nãoenzimáticas entre os carboidratos solúveis e grupos aminas dos aminoácidos. Desse modo, o aquecimento em silagens promove diminuição acentuada na digestibilidade da proteína, em decorrência de aumentos nos teores de NIDA, o qual é indisponível para os microrganismos do rúmen (Van Soest, 1994).

O teor de EE apresentou tendência de aumento de acordo com o tempo de estocagem (Tabela 8). O teor de EE foi mais elevado $(\mathrm{P}<0,05)$ nas silagens mais úmidas. $\mathrm{O}$ uso de $A B E$ reduziu $(\mathrm{P}<0,05)$ os valores de $\mathrm{EE}$ entre 0 hora e 32 dias de estocagem. O uso de APT elevou $(\mathrm{P}<0,05)$ o teor de EE nos tratamentos 650SA aos 16 dias de estocagem, e 650CA à zero hora antes da ensilagem.

O teor de NDT das silagens diminuiu significativamente $(\mathrm{P}<0,05)$ com o aumento do conteúdo de MS a partir de 16 dias de estocagem (Tabela 8), como reflexo da tendência de aumento nos conteúdos de FDN, FDA, LIG, NIDN e NIDA e redução no teor de EE. Andrade et al. (2001) observaram aumento no teor de NDT da silagem com emurchecimento, em relação à ensilagem da forragem fresca.

$O$ uso de $A B E$ reduziu $(\mathrm{P}<0,05)$ o NDT das silagens contendo 250 e $450 \mathrm{~g} / \mathrm{kg} \mathrm{MS}$, aos 32 dias de estocagem, 


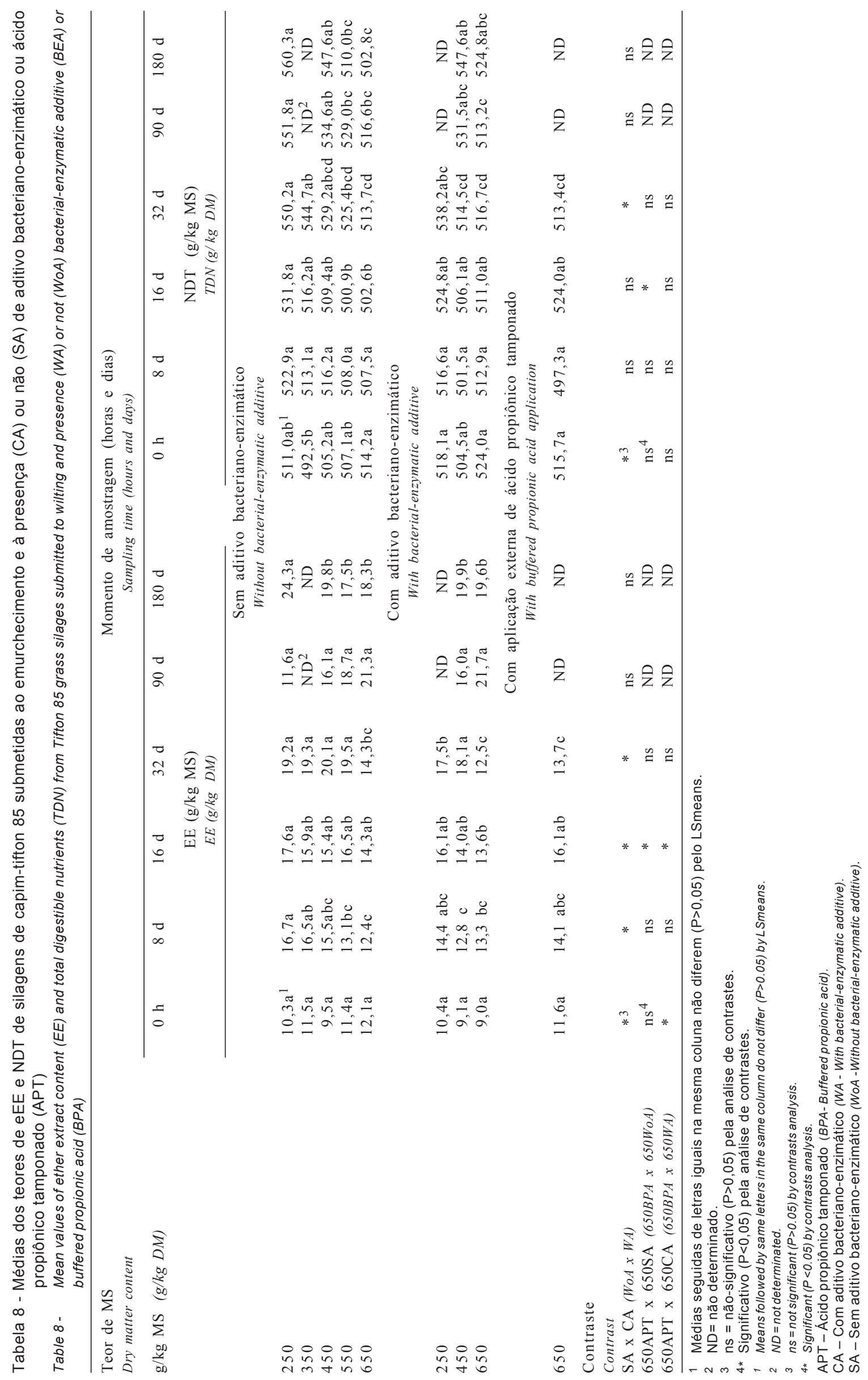


entretanto não houve efeito $(\mathrm{P}<0,05)$ no material contendo $650 \mathrm{~g} / \mathrm{kg}$ MS (Tabela 8), provavelmente em razão da tendência de aumento no teor de FDN e de redução no conteúdo de PB com o uso de ABE. Henrique \& Bose (1992) não observaram efeito do uso de ABE sobre o conteúdo de NDT de silagem de capim-elefante. Coan et al. (2001) não observaram alteração na digestibilidade in vitro da matéria seca com o uso de ABE nas silagens dos capins tanzânia e mombaça.

$\mathrm{O}$ uso de APT elevou $(\mathrm{P}<0,05)$ o teor de NDT das silagens aos 16 dias, em relação ao tratamento 650SA, provavelmente em razão da redução nos teores de FDA e LIG e do aumento no conteúdo de EE (Tabela 8).

\section{Conclusões}

O teor de matéria seca mais adequado ao processo de conservação de capim-tifton 85, obtido com o emurchecimento da forragem, e que propiciou características qualitativas de fermentação e de composição química das silagens foi de $450 \mathrm{~g} / \mathrm{kg}$ MS.

A utilização do aditivo bacteriano-enzimático, tanto em silagens de baixo como de alto teor de umidade não melhorou a qualidade da forragem conservada.

O uso de ácido propiônico tamponado não propicia melhoria nas características qualitativas de fermentação e na composição químico-bromatológica das silagens.

\section{Agradecimento}

À Fazenda Água Comprida, pelo apoio operacional e financiamento da pesquisa.

\section{Literatura Citada}

ANDRADE, J.B.; FERRARI JR., E.; LAVEZZO, W. et al. Dry matter and nutritive value of coast-cross $\mathrm{n}^{\circ} 1$ preserved as hay, silage and haylage. (Compact disc). In: INTERNATIONAL GRASSLAND CONGRESS, 19., São Pedro, 2001. Proceedings... Piracicaba: Fundação de Estudos Agrários Luiz de Queiroz, 2001.

ASSOCIATION OFFICIAL ANALYTICAL CHEMISTS - AOAC. Official methods of analysis. 14.ed. Washington, D.C.: 1984. $1141 \mathrm{p}$.

BALSALOBRE, M.A.A.; NUSSIO, L.G.; MARTHA JR.; G.B. Controle de perdas na produção de silagens de gramíneas tropicais. In: MATTOS, W.R.S. (Ed.) A produção animal na visão dos brasileiros. Piracicaba: Sociedade Brasileira de Zootecnia, 2001. p.890-911.

BERTO, J.L.; MÜHLBACH, P.R.F. Silagem de aveia preta no estádio vegetativo, submetida à ação de aditivos e ao efeito de emurchecimento. Revista Brasileira de Zootecnia, v.26, p.651-659, 1997.

CHANEY, A.L.; MARBACH, E.P. Modified reagents for determination of urea and ammonia. Clinical Chemistry, v. 8, p. $130-137,1962$.
COAN, R.M.; VIEIRA, P.F.; SILVEIRA, P.F. et al. Efeitos do inoculante enzimático-bacteriano sobre a composição química, digestibilidade e qualidade das silagens dos capins Tanzânia e Mombaça. In: REUNIÃO DA SOCIEDADE BRASILEIRA DE ZOOTECNIA, 38., 2001, Piracicaba. Anais... Piracicaba: Sociedade Brasileira de Zootecnia, 2001. p.124-126.

CRESTANA, R.F.; AGUIAR, R.N.S.; BALSALOBRE, M.A.A. et al Efeito da fermentação na fração fibra de silagens de Capim Tanzânia. In: REUNIÃO DA SOCIEDADE BRASILEIRA DE ZOOTECNIA, 38., 2001, Piracicaba. Anais... Piracicaba: Sociedade Brasileira de Zootecnia, 2001. p.354-355.

EVANGELISTA, A.R.; LIMA, J.A.; BERNARDES, T.F. Avaliação de algumas características da silagem de gramínea Estrela Roxa (Cynodon nlemfuensis Vanderyst). Revista da Sociedade Brasileira de Zootecnia, v.29, p.941-946, 2000.

HAIGH, P.M.; CHAPPLE, D.G.; POWELL, T.L. Effects of silage additives on big-bale grass silage. Grass and Forage Science, v.51, p.318-323, 1996.

HENRIQUE, W.; BOSE, M.L.V. Efeito de aditivos enzimobacterianos sobre a qualidade da silagem de Capim-elefante (Pennisetum purpureum Schum.). Revista da Sociedade Brasileira de Zooctenia, v.21, p.429-438, 1992.

HOLDEN, L.A. Comparison of methods of in vitro dry matter digestibility for ten feeds. Journal of Dairy Science, v. 82 , p.1791-1794, 1999.

KRISHNAMOORTTH, U.C.; MUSCATO, T.V.; SNIFFEN, C.J. Nitrogen fractions in selected feedstuffs. Journal of Dairy Science, v.65, n.1, p.217, 1982 .

LINDGREN, S. Can HACCP Principles be applied for silage safety? In: INTERNATIONAL SILGAE CONFERENCE, 7., Uppsala, 1999. Procedings... Upssala: Swedish University of Agricultural Science, 1999. p.51-66.

MAGALHÃES, V.J.A. RODRIGUES, P.H.M. Avaliação de inoculante microbiano na composição bromatológica, fermentação e estabilidade aeróbia de silagem pré-seca de alfafa. Revista Brasileira de Zootecnia, v.33, p.51-59, 2004

McDONALD, P., HENDERSON, A.R.; HERON; S.J.E. Biochemistry of silage. 2.ed. Marlow: Chalcombe Publication, 1991. 340p

MONTEIRO, A.L.G. Silagem pré-secada. In: SIMPÓSIO SOBRE NUTRIÇÃO DE BOVINOS, 7., Piracicaba, 1999. Anais... Piracicaba: Fundação de Estudos Agrários Luiz de Queiroz, 1999. p.97-122.

MUCK, R.E; KUNG, L. Effects of silage additives on ensiling. In SILAGE: FIELD TO FEEDBUNK, Ithaca, 1997. Proceedings... Ithaca: NRAES, 1997. p.187-199.

MÜHLBACH, P.R.F. Additives to improve the silage making process with tropical forages. In: FAO ELECTRONIC CONFERENCE ON TROPICAL SILAGE, Rome, 1999. Proceedings... Rome: FAO, 2000. p.151-164.

NATIONAL RESEARCH COUNCIL - NRC. Nutrient requeriments of dairy cattle. 7.ed. Washington, D.C.: National Academy of Sciences, 2001. 381p.

O'KIEly, P.; MOLOnEY, A.; KeATING, T. et al. Maximing output of beef within cost efficient, environmentally compatible forage conservation systems. Dunsany: Grange Reserch Centre, 1999. 64p. (Beef Production Series, 10)

PASTORINI, L.H.; BACARIN, M.A.; ABREU, C.M. Secagem de material vegetal em forno de microondas para determinação de matéria seca e análise químicas. Ciência Agrotécnica, v.26, p.1252-1258, 2002.

PITT, R.E. Silage and hay preservation. Ithaca: Northeast Regional Agricultural Engineering Service, 1990. 53p. (NRAES-5).

PLAYNE, M.J.; McDONALD, P. The buffering constituents of herbage and of silage. Journal of the Science of Food and Agriculture, v.17, p.264-268, 1966.

PRADO, H. Os solos do Estado de São Paulo: mapas pedológicos Piracicaba: Escola Superior de Agricultura Luiz de Queiroz, 1997. $102 p$. 
STATISTICAL ANALYSES SYSTEM - SAS. SAS user's guide, release 6.03. Cary: $1988.1028 \mathrm{p}$.

TOSI, H.; RODRÍGUEZ, L.R.A.; JOBIM, C.C. et al. Ensilagem do Capim-elefante cv. Mott sob diferentes tratamentos. Revista da Sociedade Brasileira de Zootecnia, v.24, p.909-916, 1995.

UMAÑA, R.; STAPLES, C.R.; BATES, D.B. et al. Effects of the digestibility of bermudagrass ensiled at two moisture contents. Journal of Animal Science, v.69, n.11, p.4588-4601, 1991.

Van SOEST, P.J. Nutritional ecology of the ruminant. 2.ed. Ithaca: Cornell University Press, 1994. 476p.
WEISS, W.P.; CONRAD, H.R.; PIERRE, R.S. A theoretically-based model for predicting total digestible nutrient values of forages and concentrates. Animal Feed Science and Technology, v.39, p.95-100, 1992.

WYSS, U. Influence pre-wilting degree on aerobic stability of grass silages. In: INTERNATIONAL SILAGE CONFERENCE, 7. 1999, Uppsala. Proceedings... Uppsala: Swedish University of Agricultural Science, 1999. p.284-285.

Recebido: 04/03/05

Aprovado:29/08/05 